\title{
Mental Depression in Young Women and Children
}

\section{John A. Hancock}

To cite this article: John A. Hancock (1907) Mental Depression in Young Women and Children, The Pedagogical Seminary, 14:4, 460-468, DOI: 10.1080/08919402.1907.10532557

To link to this article: http://dx.doi.org/10.1080/08919402.1907.10532557

曲 Published online: 30 Aug 2012.

Submit your article to this journal 2

III Article views: 4

Q View related articles $\sqsubset$ 


\section{MENTAL DEPRESSION IN YOUNG WOMEN AND CHILDREN.}

By John A. Hancock, State Normal School, Mankato, Minn.

Large numbers of young women enter our normal school each year just after they have graduated from the high school and remain from one to two years. Many of these are away from home for the first time. Homesickness, worry, "lonesomes" and "blues" are among the problems of instructor and class officer during the early weeks of each year. It was probably the memory of those weeks as well as some interest aroused in the psychology classes in the subject of insanity that raised such questions as, What are the bluas? Why do we have them? How can we prevent them? How can we overcome them?

A slight investigation showed that the available literature in regard to the problem was unsatisfactory and meagre. The students promptly decided to assist the instructor in an investigation of the subject. Papers were written by 225 young women, 8 young men, and by 60 children in sixth, seventh and eighth grades. The papers written by the young men do not materially differ from those written by the young women, but they are so few in number that they are not considered in this study. A large percentage of the students are of foreign parentage, but only two or three show any accent. All are from the smaller high schools of the state, all of which are under state supervision. All of the students reporting seem to have been under very similar influences.

Fractions in percentages are omitted in this report. Seventy per cent. of the students report their first attack of mental depression to have been between the ages of twelve and sixteen;- "about fourteen," is the common reply. Forty of them remember attacks scattered along during the preceding years. Down ${ }^{1}$ has already called attention to the not infrequent occurrence of melancholia among young children. ${ }^{2}$ Twelve out of thirty-five girls in the grades, and six out of twenty-five boys mention the same years as periods when they first began to suffer most from the blues. Eleven of the girls and four of the boys claim never to have had the blues, nor to have

1 Down: Mental affections in childhood and youth. Ch. III.

${ }^{2}$ Colvin denies this. See Ped.Sem., XIII, 9I. 
had any other of the forms of depression mentioned. Perhaps a dozen of the young women, according to their accounts, have yet to suffer in any such way.

The question, "Has there been any one year of your life when you suffered from them most frequently?" yielded very similar results. There was, however, an interesting exception. Twenty commented on the first year away from home at the normal school as the year in which they suffered most. Asked to explain frankly why, the replies indicated that for the first time the young women had found themselves forced to make decisions for themselves, and to carry considerable responsibility. Heretofore their thinking had all been done for them, and now, with anxiety they naturally awaited the outcome of their first independent efforts. One young woman speaks of her whole girlhood as a happy dream up to the time that she had left home, with no care whatever. It is, perhaps, fair to ask if it is a kindness to a daughter to rear her thus?

The cause of the frequency of depression during any one year was reported as "poor health," "nervousness," or "a disagreeable study in the high school,"-generally mathematics. Home troubles were mentioned in a few cases. Fifteen per cent. were away from home when these attacks first came on. There was the presence of a strain or stress of some kind in nearly every case. To many it seems to have been the realization of rapidly approaching womanhood with its greater responsibilities as well as the realization that a care-free childhood was rapidly receding. One student writes, "I was about twelve when I was seized with the fear that I was not good enough and I inflicted many disagreeable tasks upon myself." Many others write in the same vein, several mentioning the fact that "that year was the turning point of my life."

To the question "Have these attacks grown in frequency, or do you have them more rarely?" Forty per cent. say less frequently; twenty-seven per cent. say more frequently; thirtysix per cent. claim to suffer only at rare intervals now. A few have a hand-to-hand fight to keep them off. One girl writes, "I must have been born with them." No one of the children seems to have any habit of having them at all.

Forty per cent. of the students note alternate periods of depression and elation, the pendulum swinging too far in one direction rebounds to an extreme in the other. The following are typical statements from as many different girls :

(a) "Sometimes after great joy and good feeling there comes a like period of depression and worry."

(b) "Yes, I notice that when I am unusually happy something happens, or from some unknown cause my happiness disappears and I become as depressed as I was happy before." 
(c) "If I have been out the evening before having a splendid time I sometimes feel blue and despondent the next morning."

(d) "Some days it seems as though I could not be happier. My feelings are keyed to the highest pitch, but on the following day I experience a feeling of despising myself and everything that I have tried to accomplish.'

(e) "This feeling of elation seems to be caused by the great effort that I have to make to throw off the blues."

(f) "I know a girl who has nothing much to do and who is either always having the blues or a good time."

Fifty-two per cent. note the depressing effect upon themselves of cloudy, rainy, or stormy weather. Twenty-eight per cent. are most likely to become blue in the late afternoon or evening, often "just at dusk." Only six of the students report depression in the early morning. While the children are very susceptible to the weather, they claim it is because their activities are linited. "You can't do anything them times," says one boy. Sixteen per cent. of the students find Monday a day theydread. Sunday is a close second with ten per cent., and is a day especially disliked by the boys. Other days receive occasional mention.

In regard to the seasons twelve per cent. complain of the fall, ten per cent. of the winter, six per cent. of the spring, while only six of the students complain of the summer. The following are typical :

(a) "Rainy weather always makes me feel blue."

(b) "I am more susceptible to the blues in the latter part of the day."

(c) "I have noticed that a cloudy, disagreeable day was apt to give me a severe attack of the blues; then, cold weather too."

(d) "It seems to me one is most likely to have the blues in the evening. Monday is the most dismal day in the week to me, because we are not thoroughly started in our work. I think, too, the spring is the season when we are liable to have mental depression because it is the closing of our year's work and we are tired out."

Nothing different appears in the papers by the children concerning seasons and times when one suffers most.

The question, "Do you know of anything likely to make you blue, such as illness, loss of sleep, etc.?" aroused much interest. Forty-two per cent. report blues associated with some physical ailment; twenty per cent. with over-fatigue, twenty per cent. with loss of sleep, eighteen per cent. with discouragement due to failure to reach ideals or to succeed as well as they desired in their work. There is mention of being over- 
sensitive, of the effect of uninteresting studies, of the "hard problems of life," of the associates one has or has had, of having too little to do on some days and of worry.

One student writes, "I think the blues in my case were almost always caused by some disturbance of mind, as when I was thinking of my school work and wondering if I was going to pass. If $I$ began to fear that $I$ was going to fail it would almost always give me an attack of the blues, especially if I was tired and discouraged."

Yet another says, "After a night of worry, when I could not sleep, but tossed about with that same old question always appearing before me, in the morning I usually have an attack of blues. A bad headache is also apt to give me an attack of the blues."

Twelve of the girls in the grades confess that they are subject to depression when thinking of the outcome of their lessons. Among other causes mentioned by them are, having to do unpleasant tasks, being alone, things going wrong, lack of work, having no fun, quarrels, etc. The boys do not differ in their returns excepting that all of their statements are more brief.

The length of time that an attack of mental depression of any kind lasts is reported in the cases of thirty-four per cent. of the students to vary from a half-hour to a half-day. Fifteen per cent. suffer about a day, while thirty-three per cent. report yet longer and varying periods. With the children attacks sometimes last till the bad weather is over, but generally till something distracts their attention.

Efforts to ward off approaching blues felt to be coming, meet with varying success. The desire in all cases is to get one's attention away from himself and troubles. The favorite methods of forty-five per cent. of the students are "taking a walk," "visiting a cheerful friend," "working harder," and "doing something new and interesting." More or less will exertion seems to be necessary in the cases of the majority. Among the miscellaneous methods are "a good cry," "a nap," "mother and my religion," "playing on the piano," and "interesting myself in helping others."

Strange to say, and yet perhaps not either, three of the students say, "sometimes I don't feel inclined to ward them off. I don't know why it is, but I seem to enjoy them."

Recovery is reported to be accomplisbed by practically the same methods. Thirty-one per cent. report their troubled state of mind as "going suddenly," while with twenty-six per cent. "the blues go gradually."

The effect of depression upon sleep, appetite, dreans, work and exercise is marked. It was apparently difficult to de- 
scribe fully one's feelings when suffering from depression. The following is, perhaps, characteristic of cases of blues. "Everything seems to go wrong. One wants to be alone till it is over. One's friends don't seem to care for him any more. I feel my own shortcomings so. My troubles seem so great. I feel discouraged, lonely, depressed, abused often, or perhaps am irritable. Life does not seem worth living. Half of the time I don't know what I do want, my mind seems in such a turmoil." Mental pictures are generally represented as being blurred and indefinite when the blues are present.

Distinctions have not been clearly drawn between blues, worrying, homesickness and loneliness. They seem to shade into each other. The following are typical of replies by the students: (a) "The world seems wholly bad when I am blue. $I$ feel as though $I$ wanted to give up everything and do what I have to do for my own benefit. I seem to be an utter failure with every thing against me."

(b) "When I have the blues I feel depressed and there does n't seem to be any particular reason for it. I don't care to have any one speak to me, and if they do they don't always get a pleasant answer, for I just feel mean. I can keep up for a time this way feeling mean and angry with myself. After a time I feel weak, and then if some one says just the right thing I give up and cry and it is soon over. This may be my freak disposition rather than the blues, but at any rate they do not occur very often, only a few times in a whole year. I imagine, too, trouble that never comes, and often have a feeling, too, that something awful is going to happen."

(c) "When I am blue I think every one hates me and that I am the most abused person alive. Everything goes wrong and any little thing will make me feel very badly. I cannot see the bright side of anything. I usually get cross and want to be left alone. I feel like lying around and thinking of my troubles. I don't care to go any place. My imagination is at its best when I am blue. I get to thinking about some little thing and it soon appears like a mountain when really it ought not to bother me in the least."

The following are typical of the children's reports :

(A girl of fourteen.) "When you feel as though all the good had gone out of the world, that you could never be happy again, or else you do not feel extra fine and no one cares, you have a very bad case of the blues. To be lonesome is just as bad, I think, if not worse. I remember when I was away from home of crying every night until I cried myself to sleep from fatigue. I used to worry over tests until I brought myself up to such a pitch that $I$ failed. This gave me the blues and for a week I would feel very unhappy. Then I would pick up again and 
go to work to make up for the failure. I always take a dose of hard work when blue, or a quick walk, or ride in the fresh air. If I keep busy or do something I never feel blue, lonesome or worried.

"In the dreary winter time when you can hardly see because of sleet or snow I am most likely to get the blues because I cannot go out of doors. I was about ten years old when I was first troubled."

(A boy of twelve.) "To be blue is to be cross at everything, to be lonesome and when everything seems to go against you. Lonesome, makes me blue the most. I get over it in two or three hours. I try to keep my mind off of it. I have them mostly in the summer on cloudy, rainy days when there is n't anything to do. I have them off and on."

Nothing beyond what has been already reported in the papers of the students appears from the study of the children's papers.

Seventeen per cent. of the students speak of one thing as persisting, of the miud moving in one little circle, out of which it seems impossible to escape, and of the mental images growing ever clearer. These are probably well defined cases of worry. In these, association processes seemed to be blocked. A given situation or very frequently a possible situation only is before the mind and there is a fear more or less great that the outcome will be unfavorable. Fatigue and depression are very likely to follow or actually develop along with worry.

Nearly sixty per cent. when blue borrow much needless trouble.

Not much that is worth while seems to appear in regard to loneliness. It is recognized as a type of depression which like homesickness is largely due to the absence of favorite friends or relatives, or of absence from one's accustomed environment. It is most likely to be felt in the evening or on Saturdays and Sundays.

It is interesting to compare the conditions reported in this study with those of insanity. In general we have the peculiarities of insanity all present at various times in miniature. The sane person overcomes his troubles of a mental nature. The insane requires a very much longer time and suffers very much more and often does not recover at all. "In melancholia," according to Mercier," "the weight of the defect lies with especial severity upon the visceral nervous system and affects, secondarily, and with less urgency that moiety of the system which operates the adjustment of the self to surroundings." There are always present in melancholia intense de-

\footnotetext{
${ }^{1}$ Sanity and Insanity, p. 336 .
} 
pression of spirits, and undue lack of bodily activity together with an aversion to activity, indifferent appetite, insomnia, loss or weight, torpor of conduct and bodily processes. The sufferer feels at his worst in the morning. "As a rule the defect in the bodily activity corresponds pretty nearly with the depth of the melancholia." Insanity is the result of a stress of some kind. (Titchener.) ${ }^{1}$

Similarly the blues are largely associated with some light stress. There seems to be some exception worth noting here, however, since fifteen per cent. of the young women say that they sometimes have blues when they know of no reason whatever. Generally ${ }^{2}$ there is present either fatigue or some physical disorder, and again the strain may be mental consisting of failure, bad news, etc. Rarely do the blues trouble one of mornings unless over-fatigue is present. Otherwise they come at the end of the day, or the end of the week, or of some period which may have grown out of one's life conditions thus far.

The young women as well as the children have recognized the importance of a change of environment, of activity and of an exertion of will power to both ward off and to overcome depression. In a few cases there seems to be established regular periods for an attack of the blues. This seems to be the result of manner of life, or perhaps of a failure of all effort to overcome them. It is worth while, too, to note the establishment in some cases of periods of alternate depression and elation.

There are at hand a few data gathered at first hand during the past six years of children subject to fits of rage. In all of these cases the frequency of the attacks has grown much less. In one case the attacks lasted from one to three hours and then were followed by long periods of weakness physically. These are suggestive, too, of the attacks of mania. Perhaps it may be possible to sustain the theory that children in their growth and development show many symptoms of mental disease and disorder.

The period during which depression is most prevalent covers that of the girl's most rapid growth and development. It seems to be a period of great physical and emotional instability during which the danger is great from overstrain. We know that development may easily be warped at this time. It, too, is a time when life seems to open widely and to present within a brief time manifold possibilities to the girl. Some instinct leads her to omnivorous reading during this period as the

\footnotetext{
1 Primer of Psychology, p. 280.

2See Abrams: The Blues. Ch. III.
} 
written accounts of reading these students have done show. ${ }^{1}$ It is a time, too, when her ideals for life are largely determined, when the school and society are both making demands of no slight nature upon her; and when her health for life is being largely determined.

"An alumna," writing in the Popular Science Monthly, for May, 1904, says in regard to this period, "If her brain claims her whole vitality, how can there be any proper development. Just as very young children should give all their strength for some years solely to physical growth before the brain is allowed to make any considerable demands, so at this critical period in the life of a woman nothing should obstruct the right of way (of physical development). A year, at least, should be made especially easy for her, with neither mental nor nervous strain." 2

The remarkably small number of well women and the prevalence of disorders of nerve and stomach among them should add emphasis to the necessity of a greater, more intelligent, and more sympathetic care of girls during the years mentioned,12 to 16 . The decrease in frequency of blues after this period represents something of the growth in adjustment to maturer womanhood, of the better understanding of life's problems, and of better self-control.

In the case of those whose periods of suffering from blues have increased in number and frequency there is probably present some defect in health. There may also be the necessity of better self-control and of a better outlook on life.

The effects of season and weather have been fully discussed by Dexter." "There are many persons who are simply victims of the weather. Atmospheric changes play upon them as upon the AEolian harp. A leaden sky weighs upon them with a crushing weight and suggests all manner of unpleasant anticipations."

Presideut Hall's criticism that the American girl eats anything she happens to want, at any time and to any amount, and is often encouraged to do so, is worthy of consideration. Certainly having the more complex physical system it is more

This is illustrated by one of the students as follows: "I used to think that I did n't have as much fun as other girls and used to feel blue about that. What had been fun or good times no longer pleased me, and I felt sort of lost and out of place with the world in general. $I$ think this was due to the fact that $I$ read every minute of the time I conld get away from other work." See also Bullock in Rep. Proc. N. E. A., 1897, p. Ior 5 .

See also, Whitaker: The Health of American Girls. Pop. Sci. Mo., Sept., r907, p. 241 .

Weather Influences, p. 40. 
likely to be thrown into disorder than a man's and such habits are therefore ruinous to her, both mentally and physically.

For the teacher ambitious to succeed there is the suggestion that "forewarned is forearmed." It is possible to fight off the infiuences of undesirable weather changes, and to develop greater self-control. One can so study the problems of point of view, health, sleep, diet, recreation, and associations as to bring himself to the highest degree of efficiency in his life's work with a minimum of mental depression. 